\title{
Optimal duration of an early intervention programme for first-episode psychosis: randomised controlled trial
}

\author{
Wing Chung Chang, Gloria Hoi Kei Chan, Olivia Tsz Ting Jim, Emily Sin Kei Lau, \\ Christy Lai Ming Hui, Sherry Kit Wa Chan, Edwin Ho Ming Lee and Eric Yu Hai Chen
}

\section{Background}

Numerous early intervention services targeting young people with psychosis have been established, based on the premise that reducing treatment delay and providing intensive treatment in the initial phase of psychosis can improve long-term outcome.

\section{Aims}

To establish the effect of extending a specialised early intervention treatment for first-episode psychosis by 1 year

\section{Method}

A randomised, single-blind controlled trial (NCT01202357) compared a 1-year extension of specialised early intervention with step-down care in patients who had all received a 2-year intensive early intervention programme for first-episode psychosis.

\section{Results}

Patients receiving an additional year of specialised intervention had better outcomes in functioning, negative and depressive symptoms and treatment default rate than those managed by step-down psychiatric care.

\section{Conclusions}

Extending the period of specialised early intervention is clinically desirable but may not be feasible in lower-income countries.

\section{Declaration of interest}

None.

\section{Copyright and usage}

(c) The Royal College of Psychiatrists 2015.
Psychotic disorders including schizophrenia are severe mental illnesses that affect approximately $3 \%$ of the population ${ }^{1}$ and constitute one of the highest disease burdens globally. ${ }^{2}$ Numerous early intervention services targeting young people with psychosis have been established worldwide in the past two decades, based on the premise that reducing treatment delay and providing intensive phase-specific interventions in the initial few years of psychosis can improve long-term illness outcome. ${ }^{3}$ Superiority of early intervention services over standard care in improving clinical and functional outcomes in people with early psychosis has been consistently demonstrated by recent meta-analytic reviews. ${ }^{4,5}$ A summary of studies that evaluated the effectiveness of specialised early intervention services for patients with firstepisode or recent-onset psychosis given in online Table DS1. However, the initial therapeutic benefits achieved by such programmes may not be maintained after the service is withdrawn. In the OPUS trial, the largest randomised controlled trial (RCT) thus far evaluating the effectiveness of integrated early intervention services for psychosis, the findings of better symptom outcome and treatment adherence for early intervention over standard care at 2 years were no longer significant after 5 years of follow-up. ${ }^{6}$ Similarly, the Lambeth Early Onset (LEO) study found that improved 18-month outcomes on functioning, quality of life and hospital admission resulting from early intervention were not sustained at 5 years. ${ }^{7}$ Considerable concern is thus raised regarding the durability of beneficial effects of early intervention and how long specialised intervention should be provided to consolidate and optimise these initial treatment gains. ${ }^{8,9}$ The lack of empirical data determining the optimal duration of early intervention (usually provided for the first 1-2 years of illness) emphasises the need for research to evaluate the effectiveness of longer-term early intervention programmes for psychosis. ${ }^{6,8,9}$ It is also worth noting that both the early intervention service model and evidence supporting its effectiveness in treating psychosis were mainly derived from Western populations, particularly in Australia, Canada, the UK and Scandinavia. There is substantial variation across different regions regarding the content and intensity of early intervention services and the characteristics of patients enrolled, including age range and diagnostic distribution. ${ }^{10}$ This limits generalisability of results and precludes direct adoption of early intervention services by non-Western countries where mental healthcare is often underresourced and sociocultural contextual factors are markedly different from those of Western populations.

Hong Kong is among the few cities in Asia to implement early intervention services for psychosis. The intervention programme Early Assessment Service for Young People with Psychosis (EASY) was launched in 2001 and comprises community awareness programmes, an open referral system and a 2-year specialised intervention for young people presenting with first-episode psychosis, followed by 1-year step-down care with preserved medical follow-up but no provision of case-management service. ${ }^{11}$ Evaluation of the EASY programme using historical-control methods showed that patients receiving early intervention had better functioning, milder symptom severity, fewer suicides and hospital admissions and a lower disengagement rate than those in standard care, despite a lack of significant between-group difference in duration of untreated psychosis (DUP). ${ }^{12}$ However, consistent with increasing evidence indicating that a significant proportion of patients with early psychosis exhibit persistent functional impairment even in the presence of clinical remission, ${ }^{13,14}$ we found that only approximately a quarter of patients treated in the EASY programme fulfilled criteria for functional remission and less than half of those achieving symptomatic remission were also in functional remission. ${ }^{15}$ The existing data thus highlight an inadequacy of current early intervention services in addressing patients' functional disability. In this regard, it is suggested that extending the duration of early intervention services may be 
necessary to promote recovery, as a longer period is required for sustained and progressive functional improvement to take place after stabilisation of the initial psychotic episode with medication treatment. ${ }^{8,9}$

Our study compared a 1-year extension of a specialised early intervention service, comprising continuing phase-specific case management, with step-down psychiatric care without provision of case management in a representative cohort of Chinese patients who had received 2-year intensive treatment in the EASY programme for their first psychotic episode. To the best of our knowledge, this is the first reported RCT to examine the effectiveness of a specialised early intervention programme for psychosis with its treatment period extended beyond 2 years; currently, there are two ongoing RCTs evaluating the effectiveness of 5-year specialised early intervention services, namely the OPUS II study in Denmark and the Prevention and Early Intervention Program for Psychoses study in Canada. ${ }^{16,17}$ We predicted that, over 12 months, patients receiving the additional year of specialised early intervention would have better functional and symptom outcomes and lower default rate in out-patient treatment than patients receiving step-down treatment.

\section{Method}

A single-blind RCT was used to compare a 1-year extension of specialised early intervention (i.e. a 3-year early intervention programme) with step-down care (i.e. a 2-year early intervention programme) in patients who had received 2 years of care from the intensive early intervention service for first-episode psychosis in Hong Kong. Participants were recruited from the EASY programme between November 2010 and August 2011 and were followed up for 12 months. The EASY programme is a publicly funded, territory-wide service providing comprehensive assessment and early intervention for individuals aged 15-25 years presenting with first-episode psychosis. ${ }^{11}$ The service consists of five clinical teams, each covering a geographically defined catchment area and comprising two psychiatrists, three case managers and one social worker. The programme adopts a phase-specific, case-management approach in which each patient is assigned a case manager who provides protocol-based psychosocial interventions, namely the Psychological Intervention Programme in Early Psychosis (PIPE), ${ }^{18}$ with reference to the International Clinical Practice Guidelines for Early Psychosis, ${ }^{19}$ with local cultural adaptations. The PIPE comprises three main modules of intervention:

(a) enhancing psychological adjustment to early psychosis through in-depth engagement, comprehensive psychoeducation, adherence to medication treatment, coping and stress management, and relapse prevention (PIPE-I);

(b) psychotherapy for secondary psychiatric morbidity (PIPE-II);

(c) cognitive-behavioural therapy (CBT) for treatment-resistant psychotic symptoms (PIPE-III). ${ }^{18}$

A standardised PIPE-I module is offered by case managers to all patients and their family caregivers. As case-loads of EASY case managers (approximately 1:80) are much heavier than those of well-established early intervention services in the West, rather than providing intensive intervention such as CBT or specialised family therapy, case management of the EASY programme focuses on psychoeducation and supportive care. ${ }^{11,18}$ Emphasis is also placed on enhanced support and communications with family caregivers, who have a critical role in patient management in Hong Kong, as most patients enrolled in the programme live with their families. ${ }^{11}$ Family counselling and carer support groups are arranged if indicated. Patients with additional treatment needs such as the presence of residual symptoms or secondary depressive symptoms are referred to clinical psychologists for provision of PIPE-II and PIPE-III modules as appropriate. The programme also closely collaborates with non-governmental organisations (NGOs) which organise community-based rehabilitation programmes and vocational training for patients recovering from early psychosis. Multidisciplinary case reviews are held on a regular basis to monitor the patients' clinical progress and treatment outcomes. Patients are assertively followed up for 2 years, after which they are managed by a transitional step-down clinic in the third year of treatment, whereby medical follow-up is offered by psychiatrists who have been responsible for their care in the 2-year programme but no case management is provided (i.e. equivalent to standard psychiatric care but with 1-year continuous out-patient follow-up by psychiatrists from the EASY programme). They are then transferred to generic psychiatric services for continuous care.

Consecutive cases of patients who had received 2 years of treatment in the EASY programme following their first episode of psychosis, with a diagnosis of schizophrenia, schizophreniform disorder, schizoaffective disorder, brief psychotic disorder, delusional disorder, psychosis not otherwise specified, bipolar disorder with psychotic symptoms or depressive disorder with psychotic symptoms according to DSM-IV criteria, ${ }^{20}$ were included in the study. Exclusion criteria were intellectual disability, substance-induced psychosis, psychotic disorder due to a general medical condition or an inability to speak Cantonese Chinese for the research interview. The study was approved by the local institutional review boards. All participants provided written informed consent. For those aged under 18 years, consent was also obtained from a parent or guardian. The trial was registered with ClinicalTrials.gov (NCT01202357).

\section{Randomisation}

Following baseline assessment participants were randomly assigned in a 1:1 ratio to either extended early intervention (early intervention group) or step-down care (control group) for the next 12 months. An allocation sequence was computer-generated with a fixed block size of four. Randomisation and concealment procedures were conducted by an independent research staff member who was not involved in recruitment, clinical management or research assessment of the study participants.

\section{Treatment}

Participants in both treatment conditions were managed by psychiatrists from their respective EASY clinical teams.

\section{Extended early intervention}

Specialised early intervention was continued in the form of an additional year of case management. A trained case manager took over cases from the EASY programme and was responsible for providing care and coordinating treatment with clinicians, allied health professionals and NGOs to all participants in this group $(n=82)$ (i.e. a case-load comparable to the EASY programme). Case management closely aligned with the EASY treatment protocols, focusing specifically on functional enhancement by assisting participants to re-establish supportive social networks, resume leisure pursuits and return to work. Additionally, continuous supportive care, psychoeducation, and coping and stress management were delivered to family caregivers of each participant in the extended intervention group by the case manager. Each participant in this group received on average 16 intervention 
sessions, which were defined as case-management contacts each lasting for a minimum of $30 \mathrm{~min}$ with either clinical assessment conducted or psychosocial treatment delivered by the case manager, over 1 year. Biweekly clinical supervision was provided to case managers by senior psychiatrists who had extensive experience in early intervention for psychosis.

\section{Step-down care}

Step-down care provided out-patient medical follow-up with limited community support which focused mainly on crisis intervention. The two treatment groups did not differ from each other with respect to the intensity of medical follow-up by psychiatrists, prescription of antipsychotic medications and availability of various psychosocial interventions and community-based services.

\section{Assessment}

Trained research assistants masked to treatment allocation administered all assessments. Diagnosis of each participant was ascertained in consensus meetings attended by a senior psychiatrist and research assistants using all available information encompassing the entire follow-up period, including the Chinesebilingual Structured Clinical Interview for DSM-IV, ${ }^{21}$ informant histories and medical records. The Interview for the Retrospective Assessment of the Onset of Schizophrenia was employed to determine DUP, age and mode of onset of psychosis. ${ }^{22}$ Psychopathology was assessed using the Positive and Negative Syndrome Scale (PANSS) and Calgary Depression Scale (CDS). ${ }^{23,24}$ Symptomatic remission was measured and defined according to the operational criteria formulated by the Remission in Schizophrenia Working Group based on PANSS ratings. ${ }^{25}$ In this study we applied the symptom severity criterion in defining remission status attained at the end of 12-month follow-up. Psychopathological evaluation was conducted at baseline and at 12 months.

Psychosocial functioning was measured with the Social and Occupational Functioning Assessment Scale (SOFAS) and the Role Functioning Scale (RFS). ${ }^{26,27}$ The SOFAS provided a global functioning estimate of the individual participants, whereas the RFS, comprising four subscales, was used to assess functional levels of various domains including independent living and selfcare, work productivity, and immediate and extended social networks. Good functioning status was operationalised as simultaneous fulfilment of the following criteria: the participant attained a score above 60 (achieving functional level of 'generally functioning well though with some difficulty in social or occupational functioning' or above) in SOFAS, ${ }^{26}$ a score above 5 (achieving 'adequate' functional level or above) in RFS independent living and immediate social network subscales, ${ }^{27}$ a score above 4 in RFS work productivity (at least 'moderately functional' in independent employment, at home or in school) and extended social network subscales (at least 'moderately effective and independent' in community interactions), ${ }^{27}$ and was engaged in competitive employment (as opposed to employment in a supported or sheltered environment) at 12 months of follow-up. Functioning was assessed at baseline, at 6 months and at 12 months after study entry.

Data on sociodemographic characteristics, occupational status, hospital admission, defaults in psychiatric out-patient appointments, suicide attempts, relapse and treatment characteristics including use of second-generation antipsychotic, dose of antipsychotic medication (chlorpromazine equivalent doses were computed for analysis), ${ }^{28}$ and medication adherence of each participant were also obtained through systematic record review using out-patient and in-patient case notes as well as computerised clinical information from the hospital database. Relapse was operationally defined as recurrence or exacerbation of positive symptoms necessitating either hospital admission or adjustment of antipsychotic medication. Participants were considered as having good treatment adherence if they took more than $75 \%$ of prescribed medication (assessed on the basis of reports from patients and relatives as well as medical record review). Complete clinical record data for the follow-up year were available for all participants for analysis.

Training in the use of study instruments was provided to research assistants prior to participant recruitment. Videotaped interviews of 10 cases selected at baseline were independently rated by all research assistants for the purpose of interrater reliability evaluation. Intraclass correlation coefficients (ICCs) for PANSS general psychopathology, positive and negative symptom subscales and CDS total score were $0.92,0.96,0.91$ and 0.89 respectively, indicating good interrater reliability. Satisfactory levels of concordance were also observed in functional measures, with ICCs for SOFAS and RFS total scores being 0.93 and 0.88 respectively.

\section{Statistical analysis}

Statistical analyses were performed on an intention-to-treat basis. Primary outcome was psychosocial functioning as measured by SOFAS and RFS. Secondary outcome measures included symptom severity, service use and other clinical variables. We estimated sample size based on SOFAS as this was a key outcome measure of the study. To detect a clinically meaningful 5-point difference in SOFAS, with a power of 0.8 and $\alpha=0.05$, and to allow for a withdrawal rate of 20\%, 160 participants were required for the study. To test whether the two treatment groups were comparable at intake after randomisation, between-group differences in sociodemographic factors, baseline clinical profiles, treatment characteristics, symptom and functioning scores at entry were examined using the chi-squared test and independent $t$-test, as appropriate. To determine group differences in functional and symptom outcome measures, a series of linear mixed model (LMM) analyses with random intercepts and slopes were employed, ${ }^{29}$ using R version 3.02 for Windows. The final models were optimised by defining the covariance structure with assessment time-points as within-individual factors (i.e. repeated effects) and treatment group as between-individual factors to estimate longitudinal changes of outcome variable across follow-up period, in particular the presence of any significant group $\times$ time interactions, followed by the specific intervals (i.e. baseline to 6 months or 6-12 months) in which the two groups differed in functioning score change. Between-group comparisons of symptom and functional outcomes at follow-up were performed. Implementation of LMM analysis is recommended as a preferred statistical method of outcome analysis in clinical trials, as these models can address missing outcome data by allowing the analysis of all available data on the assumption that data are missing at random, conditional on adjustment for covariates and baseline observed scores. ${ }^{29}$ Rates of attaining symptomatic remission and good functional status at 12 months were compared between the two groups. To address potential effects of attrition bias, sensitivity analysis was conducted based on a worst-case scenario, i.e. participants lost to follow-up were considered not to be in remission and to have poor functional status. Treatment characteristics at follow-up and other outcome variables were compared between the two groups. Duration of untreated psychosis was log-transformed owing to its skewed distribution. All statistical analyses were two-tailed with level of significance set at $P<0.05$. 


\section{Results}

A total of 160 patients were enrolled and randomly assigned to the extended early intervention group $(n=82)$ or the steppedcare (control) group $(n=78)$. The 160 participants were predominantly single $(96 \%)$ and $51 \%$ were male. The mean age of the sample at intake was 22.9 years $($ s.d.=3.2). The median DUP of the sample was 13 weeks $($ mean $=36$, s.d. $=52.5)$. Diagnoses of the cohort were schizophrenia spectrum disorder $(n=131)$, affective psychosis $(n=15)$ and other non-affective psychoses $(n=14)$. Four participants withdrew from the study (Fig. 1). There was no significant between-group difference in discontinuation rate $(P=0.62)$, sociodemographic profile or baseline clinical, functional and treatment characteristics (Tables 1 and 2).

\section{Functional outcomes}

There was no significant difference between the two groups in functional outcomes at 6 months (Table 2). After 12 months, participants in the extended intervention group had significantly better global functioning, as revealed by higher SOFAS and RFS total scores, and more favourable outcomes in independent living skills, work productivity, and relationships of both immediate and extended social networks as measured by RFS subscales, than those in control group (Table 2). A significantly greater proportion of participants in the intervention group achieved good functional status compared with those in control group at 12 months (Table 3). No significant between-group difference was noted in attainment of full-time work at the 12-month follow-up.

The longitudinal analysis showed significant group $\times$ time interactions in SOFAS score, with significant changes in functioning between baseline and 6 months as well as between 6 months and 12 months (Table 4). Participants in the intervention group had significant improvement in SOFAS score from baseline to 6 months $(P<0.001)$ and from 6 months to 12 months $(P<0.001)$, whereas there was no significant change in SOFAS score across the study period in the control group (Fig. 2). No significant main between-individual effect of treatment allocation on SOFAS rating was observed. Regarding the change in RFS ratings over time, LMM analyses indicated significant group $\times$ time interactions in total score and scores on work productivity, independent living, and immediate and extended social network subscales (Table 4). Significant changes between baseline and 6 months in work productivity and immediate social network subscale scores, and significant changes between 6 months and 12 months in RFS total score, work productivity, independent living, immediate and extended social network subscale scores were observed. The intervention group was found to have significant improvements in RFS total score $(P<0.001)$, work productivity $(P<0.001)$, immediate $(P<0.01)$ and extended $(P<0.01)$ social network subscale scores from baseline to 6 months and from 6 months to 12 months of follow-up. A significant increase in independent living subscale score $(P<0.01)$ was found in the intervention group from baseline to 6 months (Fig. 2). Conversely, participants in the control group failed to show significant improvement in RFS total and any of the subscale scores from 6 months to 12 months. The RFS total $(P<0.01)$, independent living $(P<0.01)$ and extended social network subscale $(P<0.01)$ scores were significantly improved in the control group from baseline to 6 months (Fig. 2). Otherwise, there was no significant main between-individual effect of treatment allocation on any of the RFS ratings. Taken together, participants in the early intervention group had ongoing functional gains across 12 months whereas those in the control group failed to attain any sustained functional improvement after study entry.

\section{Symptoms and other secondary outcomes}

Table 3 summarises the differences between treatment groups in 12 -month outcomes on symptom severity as well as other clinical and service use variables. The intervention group had significantly fewer negative and depressive symptoms, lower PANSS general psychopathology scores and fewer defaults in psychiatric outpatient appointments than the control group. Significant group $\times$ time interactions were noted in outcomes on negative symptoms $(t=2.4, P<0.05)$, depressive symptoms $(t=3.0, P<0.01)$ and PANSS general psychopathology scores $(t=2.9, P<0.01)$. No significant between-group difference was observed with respect to medication treatment characteristics, positive symptom level, length of in-patient stay or rates of symptomatic remission, relapse and attempted suicide (Table 3).

\section{Discussion}

We found that patients receiving an additional year of specialised early intervention had significantly better functioning, fewer negative and depressive symptoms and a lower default rate in out-patient treatment than the control group. With regard to functional outcome, two important findings emerged: first, patients in both treatment groups exhibited a moderate degree of functional disability at baseline (i.e. after completing the 2-year

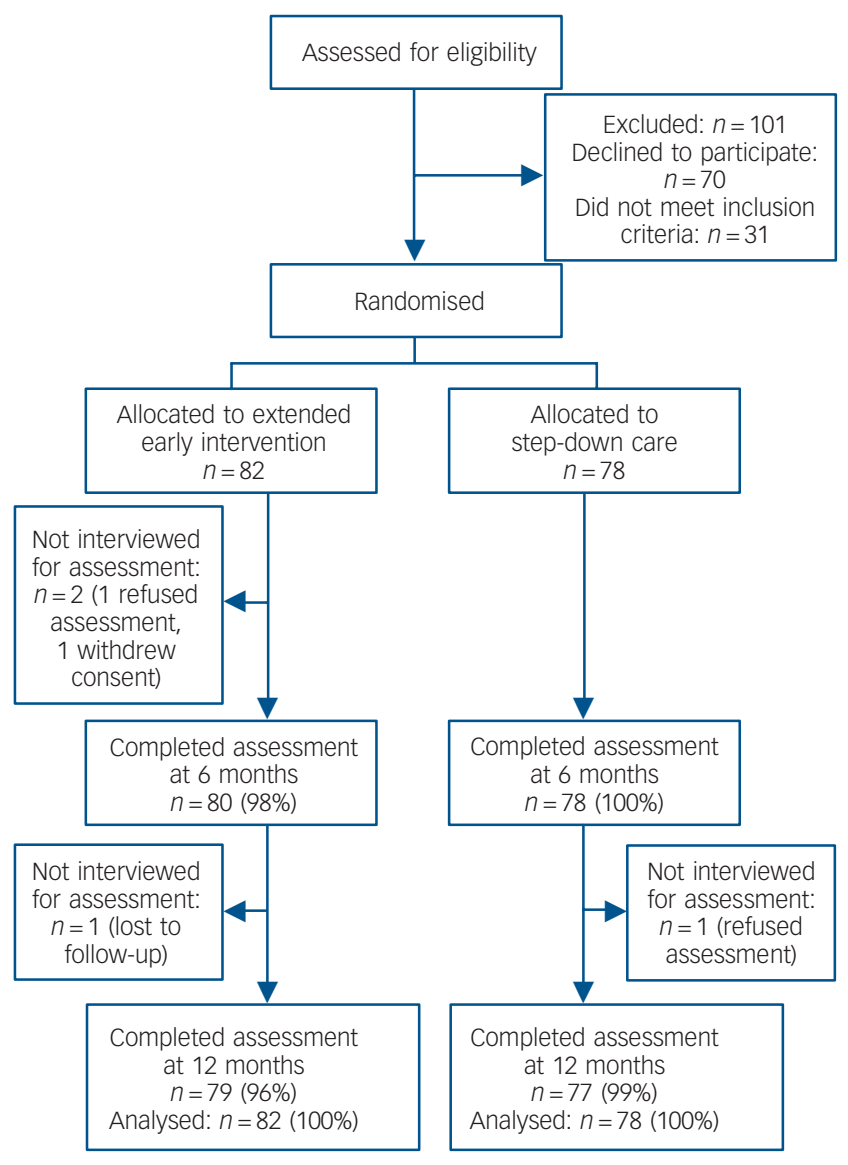

Fig. 1 Flow of patients through the study. 
Table 1 Baseline demographic, clinical and treatment characteristics of the sample

\begin{tabular}{|c|c|c|c|c|}
\hline & $\begin{array}{l}\text { Extended intervention } \\
\text { group }(n=82)\end{array}$ & $\begin{array}{l}\text { Control group } \\
\qquad(n=78)\end{array}$ & $\operatorname{tor} \chi^{2}$ & $P$ \\
\hline \multicolumn{5}{|l|}{ Demographic characteristics } \\
\hline Age at study entry, years: mean (s.d.) & $23(3.0)$ & $22.8(3.3)$ & 0.31 & 0.756 \\
\hline Male gender, \% (n) & $50(41)$ & $51(40)$ & 0.03 & 0.871 \\
\hline Marital status: single, \% (n) & $94(77)$ & $97(76)$ & $1.19^{\mathrm{a}}$ & 0.444 \\
\hline Education: tertiary level or above, \% (n) & $24(20)$ & $27(21)$ & 0.14 & 0.714 \\
\hline Employed at baseline, \% (n) & $60(50)$ & $65(51)$ & 0.33 & 0.563 \\
\hline \multicolumn{5}{|l|}{ Illness onset characteristics } \\
\hline Age at onset of psychosis, years: mean (s.d.) & $20.2(2.9)$ & $20.3(3.3)$ & -0.17 & 0.863 \\
\hline Gradual onset of psychosis $<1$ month, $\%(n)$ & $66(54)$ & $56(44)$ & 1.50 & 0.220 \\
\hline \multicolumn{5}{|l|}{ Duration of untreated psychosis, weeks } \\
\hline Median & 9 & 16 & & \\
\hline LogDUP: mean (s.d.) $)^{b}$ & $1.9(0.7)$ & $2.0(0.8)$ & -0.74 & 0.459 \\
\hline \multicolumn{5}{|l|}{ Three-year longitudinal diagnosis, \% (n) } \\
\hline Schizophrenia spectrum disorder ${ }^{\mathrm{C}}$ & $84(69)$ & $80(62)$ & 1.48 & 0.476 \\
\hline Affective psychosis $^{d}$ & $10(8)$ & $9(7)$ & & \\
\hline Other non-affective psychosis ${ }^{\mathrm{e}}$ & $6(5)$ & $12(9)$ & & \\
\hline \multicolumn{5}{|l|}{ Past clinical and treatment parameters, $\%(n)$} \\
\hline Psychiatric hospital admission & $66(54)$ & $60(47)$ & 0.54 & 0.463 \\
\hline Default of psychiatric follow-up & $43(35)$ & $40(31)$ & 0.14 & 0.706 \\
\hline History of suicide attempt & $6(5)$ & $4(3)$ & $0.43^{\mathrm{a}}$ & 0.720 \\
\hline \multicolumn{5}{|l|}{ Baseline symptom severity: mean (s.d.) } \\
\hline PANSS positive symptom score & $9.3(3.3)$ & $9.1(2.9)$ & 0.60 & 0.551 \\
\hline PANSS negative symptom score & $11.7(5.2)$ & $12.3(5.6)$ & -0.74 & 0.464 \\
\hline PANSS general psychopathology score & $24.5(7.4)$ & $24.5(6.3)$ & -0.01 & 0.990 \\
\hline CDS total score & $2.8(3.4)$ & $2.9(3.5)$ & -0.06 & 0.956 \\
\hline \multicolumn{5}{|l|}{ Baseline treatment characteristics } \\
\hline \multicolumn{5}{|l|}{ Antipsychotic treatment } \\
\hline Not taking antipsychotic, \% (n) & $7(6)$ & $5(4)$ & $0.37^{\mathrm{a}}$ & 0.833 \\
\hline Use of SGA, \% (n) & $82(67)$ & $85(66)$ & & \\
\hline CPZ equivalent dose, mg: mean (s.d.) & $307(256)$ & $300(253)$ & 0.17 & 0.869 \\
\hline \multicolumn{5}{|c|}{$\begin{array}{l}\text { CDS, Calgary Depression Scale; CPZ, chlorpromazine; DUP, duration of untreated psychosis; PANSS, Positive and Negative Syndrome Scale; SGA, second-generation antipsychotic. } \\
\text { a. Fisher's exact test was applied. } \\
\text { b. Duration of untreated psychosis was log-transformed for parametric analysis owing to its skewed distribution. } \\
\text { c. Schizophrenia, schizoaffective disorder or schizophreniform disorder. } \\
\text { d. Includes bipolar affective disorder and depressive disorder with psychotic symptoms. } \\
\text { e. Includes brief psychotic disorder, delusional disorder and psychosis not otherwise specified. }\end{array}$} \\
\hline
\end{tabular}

\begin{tabular}{|c|c|c|c|}
\hline & $\begin{array}{l}\text { Extended intervention } \\
\text { group }(n=82)\end{array}$ & $\begin{array}{l}\text { Control group } \\
\qquad(n=78)\end{array}$ & $P$ \\
\hline \multicolumn{4}{|l|}{ Baseline scores: mean (s.d.) } \\
\hline SOFAS & $57.5(14.3)$ & $57.9(13.6)$ & 0.867 \\
\hline RFS total score & $19.2(4.2)$ & $19.8(3.9)$ & 0.354 \\
\hline RFS work productivity score & $4.1(1.8)$ & $4.6(1.5)$ & 0.096 \\
\hline RFS independent living score & $6.1(1.0)$ & $6.2(0.8)$ & 0.220 \\
\hline RFS immediate social network score & $4.9(2.1)$ & $5.0(1.3)$ & 0.665 \\
\hline RFS extended social network score & $4.1(1.4)$ & $4.0(1.5)$ & 0.663 \\
\hline \multicolumn{4}{|l|}{ Scores at 6-month follow-up: mean (s.d.) } \\
\hline SOFAS & $62.3(13.3)$ & $58.7(11.1)$ & 0.203 \\
\hline RFS total score & $21.1(3.7)$ & $20.7(3.3)$ & 0.537 \\
\hline RFS work productivity score & $4.8(1.6)$ & $4.7(1.4)$ & 0.727 \\
\hline RFS independent living score & $6.3(0.8)$ & $6.5(0.6)$ & 0.110 \\
\hline RFS immediate social network score & $5.3(0.9)$ & $5.1(1.0)$ & 0.111 \\
\hline RFS extended social network score & $4.6(1.2)$ & $4.5(1.3)$ & 0.352 \\
\hline \multicolumn{4}{|l|}{ Scores at 12-month follow-up: mean (s.d.) } \\
\hline SOFAS & $64.8(13.1)$ & $57.9(12.7)$ & $0.001 * *$ \\
\hline RFS total score & $22.1(3.2)$ & $20.3(3.7)$ & $0.002 * *$ \\
\hline RFS work productivity score & $5.1(1.4)$ & $4.7(1.5)$ & $0.045^{\star}$ \\
\hline RFS independent living score & $6.5(0.6)$ & $6.2(1.0)$ & $0.036^{*}$ \\
\hline RFS immediate social network score & $5.5(0.9)$ & $5.1(1.0)$ & $0.002 * *$ \\
\hline RFS extended social network score & $4.9(1.0)$ & $4.3(1.3)$ & $0.004^{* *}$ \\
\hline
\end{tabular}




\begin{tabular}{|c|c|c|c|c|}
\hline & $\begin{array}{l}\text { Extended early } \\
\text { intervention group } \\
\qquad(n=82)\end{array}$ & $\begin{array}{l}\text { Control group } \\
\qquad(n=78)\end{array}$ & $t$ or $\chi^{2}$ & $P$ \\
\hline \multicolumn{5}{|l|}{ Symptom severity at 12 months ${ }^{a}$} \\
\hline \multicolumn{5}{|l|}{ Subscale scores: mean (s.d.) } \\
\hline PANSS positive symptoms & $8.3(2.5)$ & $8.6(2.8)$ & -0.68 & 0.50 \\
\hline PANSS negative symptoms & $8.5(2.5)$ & $9.8(3.8)$ & -2.5 & $0.013^{*}$ \\
\hline PANSS general psychopathology & $19.2(3.7)$ & $21.1(5.0)$ & -2.6 & $0.01 *$ \\
\hline CDS total score & $0.9(1.6)$ & $1.8(2.7)$ & -2.5 & $0.008^{*}$ \\
\hline Symptomatic remission, $\%(n)^{\mathrm{a}}$ & $78(64)$ & $68(53)$ & 2.7 & 0.150 \\
\hline \multicolumn{5}{|l|}{ Global functioning at 12 months } \\
\hline Good functioning status, \% (n) & $35(29)$ & $19(15)$ & 5.2 & $0.022 *$ \\
\hline \multicolumn{5}{|l|}{ Other outcome measures during follow-up } \\
\hline Psychiatric hospital admission, \% (n) & $16(13)$ & $10(8)$ & 0.3 & 0.353 \\
\hline Length of hospital stay, days: mean (s.d.) ${ }^{b}$ & $7.4(20.6)$ & $3.5(12.8)$ & 1.5 & 0.146 \\
\hline Default in out-patient appointment, \% (n) & $18(15)$ & $33(26)$ & 4.7 & $0.029 *$ \\
\hline Suicide attempt, \% (n) & $0(0)$ & $0(0)$ & & \\
\hline Relapse of psychotic episode, \% (n) & $16(13)$ & $19(15)$ & 0.3 & 0.574 \\
\hline Full-time work at 12 months, \% (n) & $56(46)$ & $47(37)$ & 1.2 & 0.273 \\
\hline \multicolumn{5}{|l|}{ Treatment characteristics at follow-up } \\
\hline \multicolumn{5}{|l|}{ Antipsychotic treatment at 6 months } \\
\hline Not taking antipsychotic, \% (n) & $8(7)$ & $6(5)$ & $0.5^{\mathrm{c}}$ & 0.796 \\
\hline Use of SGA, \% (n) & $79(65)$ & $83(65)$ & & \\
\hline \multicolumn{5}{|l|}{ Antipsychotic treatment at 12 months } \\
\hline Not taking antipsychotic, \% (n) & $10(8)$ & $8(6)$ & 0.4 & 0.815 \\
\hline Use of SGA, \% (n) & $78(64)$ & $82(64)$ & & \\
\hline \multicolumn{5}{|l|}{ CPZ equivalent dose, mg: mean (s.d.) } \\
\hline At 6 months & $302(238)$ & $323(300)$ & -0.5 & 0.640 \\
\hline At 12 months & $322(276)$ & $301(295)$ & 0.4 & 0.618 \\
\hline Good treatment adherence, \% (n) & $83(68)$ & 79 (62) & 0.2 & 0.694 \\
\hline
\end{tabular}

\begin{tabular}{|c|c|c|c|c|c|}
\hline & \multicolumn{3}{|c|}{ Group $\times$ time interaction (overall model) } & \multirow{2}{*}{$\begin{array}{c}\text { Baseline to } 6 \text { months } \\
P\end{array}$} & \multirow{2}{*}{$\begin{array}{c}6 \text { to } 12 \text { months } \\
P\end{array}$} \\
\hline & $\mathrm{t}$ & s.e. & $P$ & & \\
\hline SOFAS score & 4.49 & 0.128 & $<0.0001$ & $0.023^{*}$ & $<0.0001$ \\
\hline RFS total score & 4.15 & 0.039 & $<0.0001$ & 0.068 & $<0.0001$ \\
\hline RFS work productivity score & 3.58 & 0.016 & $0.0004^{* * *}$ & $0.033^{*}$ & $0.0003 * * *$ \\
\hline RFS independent living score & 1.98 & 0.010 & $0.0481^{*}$ & 0.302 & $0.0129 *$ \\
\hline RFS immediate social network score & 3.60 & 0.012 & $0.0004^{* * *}$ & $0.019^{*}$ & $0.0003^{* * *}$ \\
\hline RFS extended social network score & 2.69 & 0.014 & $0.0076^{* \star}$ & 0.497 & $0.0027^{* *}$ \\
\hline
\end{tabular}

early intervention programme). Our results thus concur with accumulating evidence showing that people with early psychosis still experience significant functional impairment even when clinical stabilisation and remission have been achieved. ${ }^{13-15}$ Second, different functional trajectories were observed between treatment groups across the study period; although there was no significant between-group difference in functioning either at intake or at 6-month follow-up, patients in the intervention group displayed progressive functional improvement, whereas those in the control group failed to show any significant enhancement of functioning over 12 months. Hence, these results support our primary hypothesis that the extended early intervention service would be superior to step-down care in improving the functional outcome of patients with early psychosis. In fact, promoting recovery and facilitating uptake of educational, social and vocational opportunities are identified as key elements in early intervention for young people with psychosis. ${ }^{30}$ One recent study further indicated that functional recovery status achieved in the early illness course strongly predicted long-term outcomes on social functioning and negative symptoms. ${ }^{31}$ Longer-term early intervention services may thus be crucial to consolidation and sustained improvement of initial functional gains. This also aligns with stage-specific processes regarding the course of illness, wherein symptom resolution and clinical stabilisation take place at an earlier stage followed by gradual functional improvement which occurs later and requires substantially longer to achieve.

\section{Secondary outcomes}

An additional year of specialised early intervention was relatively effective in reducing negative symptoms, which nonetheless remained an unmet therapeutic need and were associated with poor 
(a)

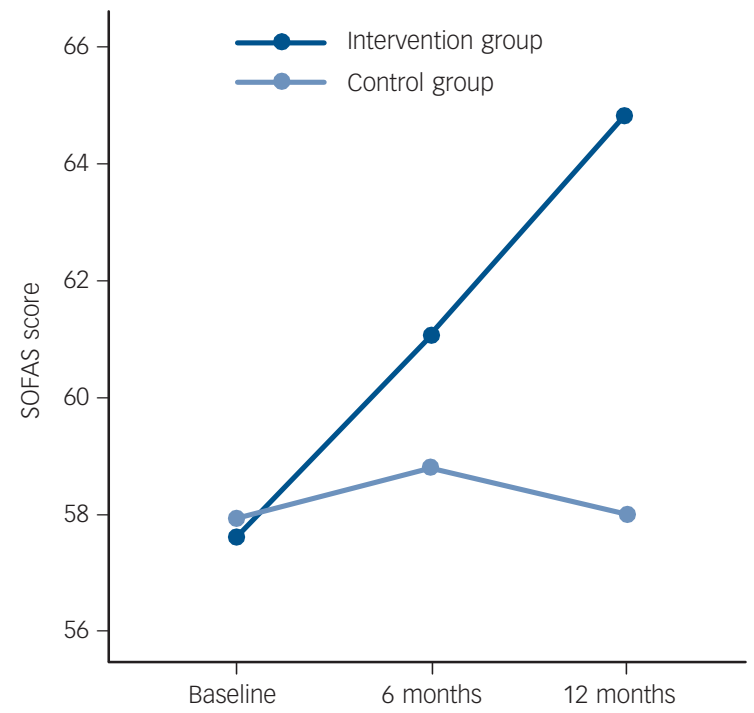

(c)

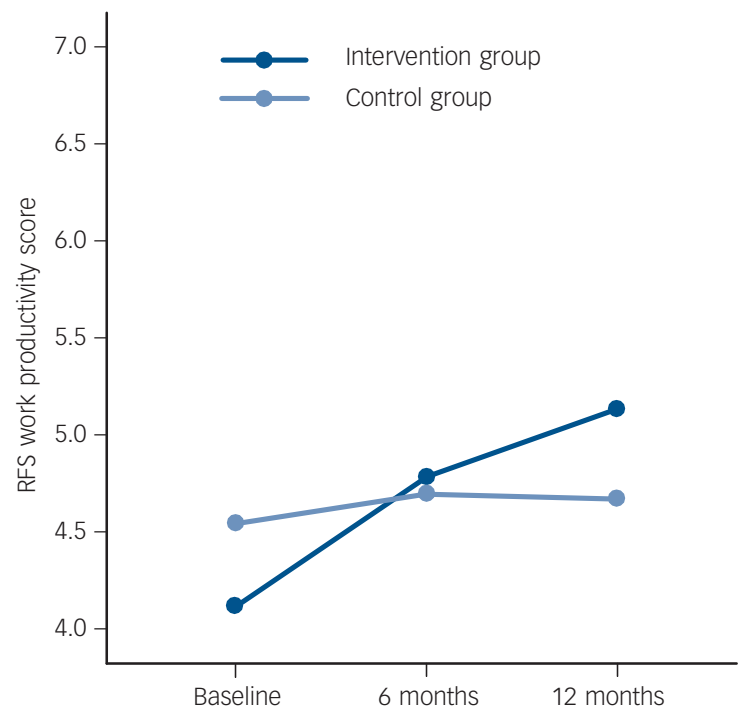

(e)

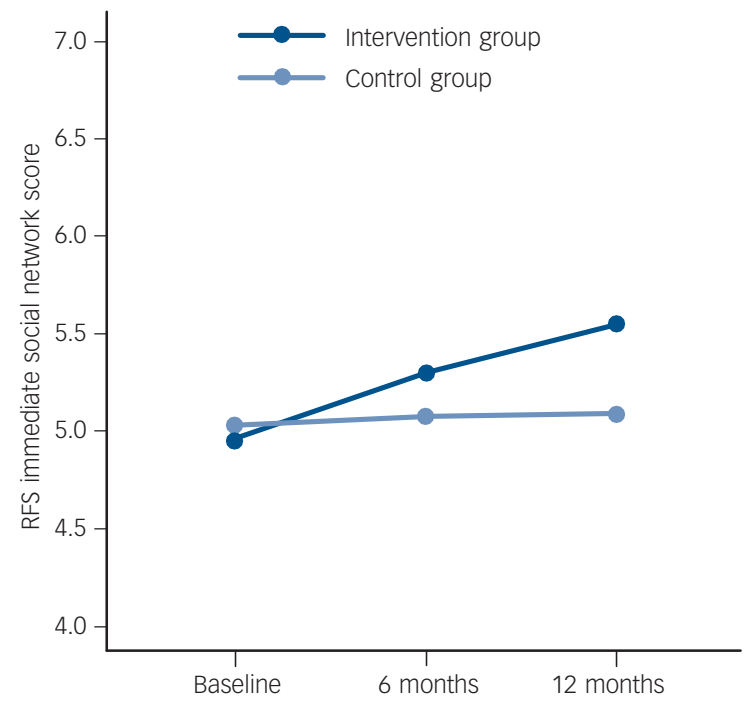

(b)

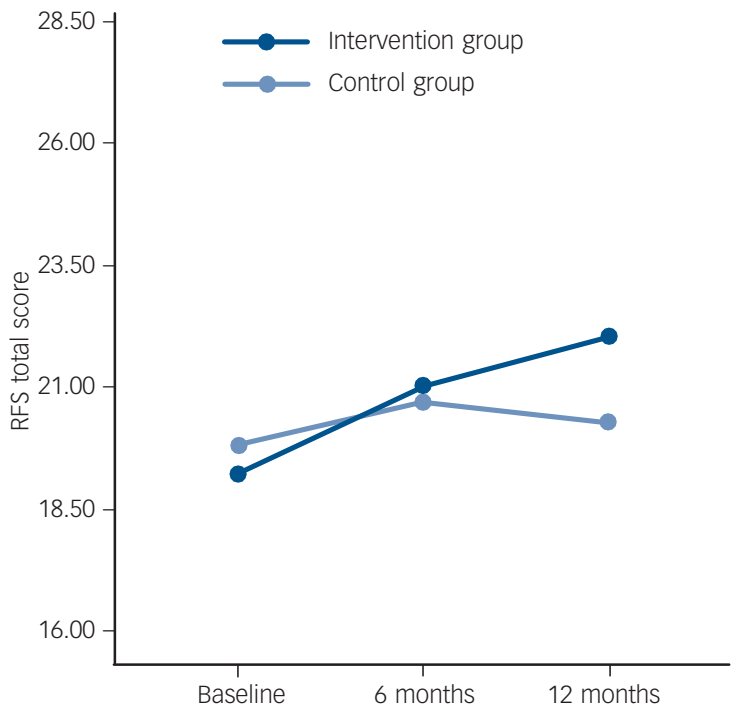

(d)

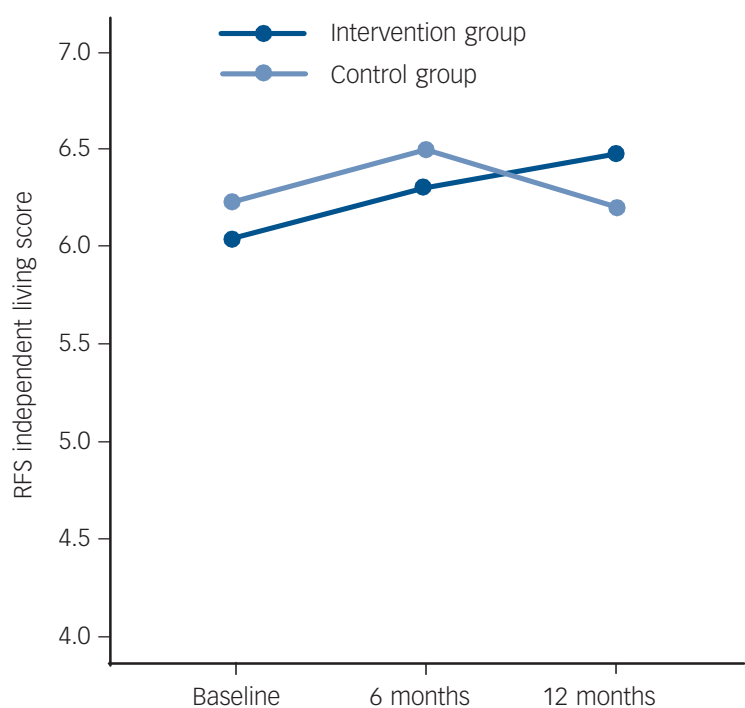

(f)

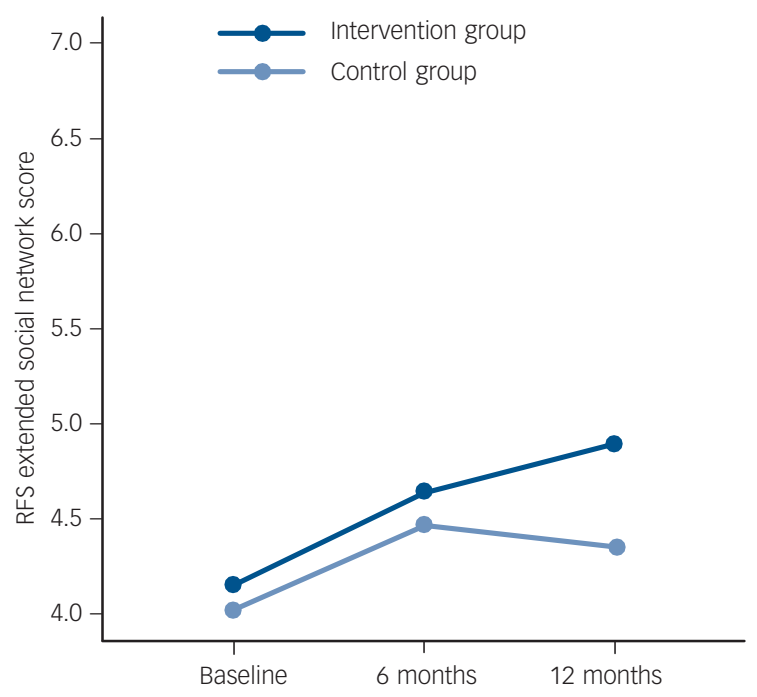

Fig. 2 Longitudinal change in functioning scores across 12-month follow-up in the extended early intervention and step-down care groups: (a) change in Social and Occupational Functioning Assessment Scale (SOFAS) score; (b) change in Role Functioning Scale (RFS) total score (c) change in RFS work productivity score; (d) change in RFS independent living score; (e) change in RFS immediate social network score; $(f)$ change in RFS extended social network score. Significant group $\times$ time interactions were noted in all functional outcome scores as revealed by repeated-measures analyses of variance except RFS extended social network domain (see Table 4 for detailed results of longitudinal analyses of functioning scores). 
functional outcome and limited response to pharmacotherapy. ${ }^{32,33}$ The intervention also compared favourably with step-down treatment in ameliorating depressive symptoms at 12-month follow-up. This is of critical clinical significance, as research has repeatedly demonstrated that depressive symptoms frequently occur in people with psychotic disorders and are closely associated with heightened suicide risk, ${ }^{34,35}$ particularly in the early stage of the illness. ${ }^{36,37}$ Consistent with previous reports, we found that patients in the intervention group had a significantly lower outpatient default rate than those receiving standard care; ${ }^{4,5}$ on the other hand, we failed to demonstrate any additional benefit of the intervention in relation to positive symptom severity, attainment of symptomatic remission or rate of relapse. Our findings thus concurred with some, ${ }^{38-40}$ but not all, ${ }^{41}$ prior RCTs evaluating the effectiveness of phase-specific, service-level intervention for early psychosis. One possible explanation for the lack of significant between-group differences in positive symptom outcome and relapse rate was that extended early intervention focused primarily on improving psychosocial functioning by means of specialised case management, and there was no difference between the intervention and control groups with respect to pharmacological treatment. It is also possible that as our patients were mostly clinically stabilised at entry after completion of the EASY programme, it was unlikely that a significant further reduction of positive symptoms could be observed. In agreement with previous RCTs comparing early intervention services with standard care in patients with early psychosis, ${ }^{38-41}$ we found that the two treatment groups did not differ in the rate of suicide attempt. Our result of lack of significant difference between early intervention and control groups in hospital admission rates was, however, contrary to a number of past RCTs, ${ }^{41,42}$ and historical case-control comparison studies, ${ }^{12,43,44}$ which demonstrated that patients who received early intervention services had fewer admissions than those in standard care. It is plausible that an absence of group difference in relapse rates during follow-up may partly explain the null finding on rate of in-patient treatment. The discrepant result may also be attributable to the difference in case-loads between our extended early intervention and the early intervention services of some Western countries, with the former having a significantly higher patient-to-case manager ratio, which might lower the capacity of the service to reduce the risk of readmission to hospital. Alternatively, the modest sample size and short follow-up duration of our study may have limited its power to examine the treatment effects of extended early intervention on readmission, as well as the suicide risk.

It is, however, important to note that our study compared an early intervention service with low resources and high case-loads with well-established early psychosis programmes implemented in some Western countries; our results therefore should be generalised to other populations with caution. Extending the early intervention service from 2 years to 5 years, to encompass the entire hypothetically critical period of psychosis, ${ }^{45}$ might improve our patients' prognosis. However, in the context of competing demands and budgetary constraints, lengthening the intervention to 5 years might not be feasible or affordable in most non-Western regions, even in some relatively affluent Asian communities. Three-year specialised early intervention programmes may thus represent an economically viable alternative.

The strengths of the study included successful randomisation, lack of differential attrition between treatment groups, masking of the research staff assessing outcomes to treatment allocation, low withdrawal rate, comprehensive evaluation of functional outcomes encompassing both global functioning and various specific functional dimensions, and availability of complete clinical record data regarding medication treatment, follow-up defaults and hospital admission for all participants. Several methodological limitations, however, warrant consideration in interpreting the study results. First, as the sample was recruited from the EASY programme, which treated patients aged 15-25 years only, our results may not be generalisable to people who were older at onset of psychosis. Second, the short follow-up period precluded us from addressing the question of whether therapeutic benefits attained from an additional year of specialised early intervention could be maintained after service withdrawal. Reassessment at a later time is required to examine this issue.

\section{Further research}

This was the first RCT to provide evidence of the efficacy of extending an early intervention service for psychosis beyond 2 years. Our results indicated that patients receiving an additional year of specialised early intervention had better outcomes in functioning, negative symptoms and depressive symptoms, and lower treatment default rates, than those managed by step-down psychiatric care. Further follow-up is required to clarify the sustainability of treatment effects of this extended intervention.

\begin{abstract}
Wing chung chang, MRCPSych, FHKCPsych, Gloria Hoi Kei Chan, MPhil, Olivia Tsz Ting Jim, BsocSc, Department of Psychiatry, University of Hong Kong; Emily Sin Kei Lau, BsocSC, Department of Psychiatry, Queen Mary Hospital, Hong Kong; Christy Lai Ming Hui, PhD, sherry Kit Wa Chan, MRCPsych, Edwin Ho Ming Lee, MRCPsych, FHKCPsych, Department of Psychiatry, University of Hong Kong; Eric Yu Hai Chen, MD, Department of Psychiatry, University of Hong Kong and State Key Laboratory of Brain and Cognitive Sciences, University of Hong Kong
\end{abstract}

Correspondence: Wing Chung Chang, Department of Psychiatry, Queen Mary Hospital, Hong Kong. Email: changwc@hku.hk

First received 17 Apr 2014, final revision 11 Jul 2014, accepted 6 Aug 2014

\section{Funding}

The study was supported by a grant from the Commissioned Research on Mental Health Policy and Services (SMH-29) of the Food and Health Bureau, Government of Hong Kong Special Administrative Region. The funding body had no involvement in any aspect of the study or manuscript preparation. E.Y.H.C has been a member of the paid advisory board for Otsuka and has received educational grant support from Janssen-Cilag, Eli Lilly, Sanofi-Aventis and Otsuka. E.H.M.L has been a member of the paid advisory boards for Eli Lilly and AstraZeneca.

\section{Acknowledgements}

The authors thank all the coordinating clinicians and staff from the psychiatric units involved in the study. We thank Dr H.C. So for his kind assistance in statistical analysis using R software. We are also grateful to the individuals who participated in the study.

\section{References}

1 Van OS J, Kapur S. Schizophrenia. Lancet 2009; 374: 635-45.

2 Whiteford HA, Degenhardt L, Rehm J, Baxter AJ, Ferrari AJ, Erskine HE, et al. Global burden of disease attributable to mental and substance use disorders: findings from the Global Burden of Disease Study 2010. Lancet 2013; 382: 1575-86.

3 McGlashan T, Johannessen J. Early detection and intervention with schizophrenia: rationale. Schizophr Bull 1996; 22: 201-22.

4 Harvey PO, Lepage M, Malla A. Benefits of enriched intervention compared with standard care for patients with recent-onset psychosis: a meta-analytic approach. Can J Psychiatry 2007; 52: 464-72.

5 Bird V, Premkumar P, Kendall T, Whittington C, Mitchell J, Kuipers E. Early intervention services, cognitive-behavioural therapy and family intervention in early psychosis: systematic review. Br J Psychiatry 2010; 197: 350-6.

6 Bertelsen M, Jeppesen P, Petersen L, Thorup A, Ohlenschlaeger J, Quach P, et al. Five-year follow-up of a randomized multicenter trial of intensive early intervention vs standard treatment for patients with a first episode of psychotic illness. Arch Gen Psychiatry 2008; 65: 762-71. 
7 Gafoor R, Nitsch D, McCrone P, Craig TK, Garety PA, Power P, et al. Effect of early intervention on 5-year outcome in non-affective psychosis. Br J Psychiatry 2010; 196: 372-6.

8 Friis S. Early specialised treatment for first-episode psychosis: does it make a difference? Br J Psychiatry 2010; 196: 339-40.

9 Singh SP. Early intervention in psychosis. Br J Psychiatry 2010; 196: 343-5.

10 Edwards J, Harris MG, Bapat S. Developing services for first-episode psychosis and the critical period. Br J Psychiatry 2005; 187 (suppl. 48): s91-7.

11 Tang JYM, Wong GHY, Hui CLM, Lam MM, Chiu CP, Chan SK, et al. Early intervention for psychosis in Hong Kong: the EASY programme. Early Interv Psychiatry 2010; 3: 214-9.

12 Chen EYH, Tang JYM, Hui CLM, Chiu CP, Lam MM, Law CW, et al. Three-yea outcome of phase-specific early intervention for first-episode psychosis: a cohort study in Hong Kong. Early Interv Psychiatry 2011; 5: 315-23.

13 Petersen L, Thorup A, Oqhlenschlaeger J, Christensen TO, Jeppesen P, Krarup G, et al. Predictors of remission and recovery in a first-episode schizophrenia spectrum disorder sample: a 2-year follow-up of the OPUS trial. Can J Psychiatry 2008; 53: 660-70

14 Henry LP, Amminger GP, Harris MG, Yuen HP, Harrigan SM, Prosser AL, et al. The EPPIC follow-up study of first-episode psychosis: longer-term clinical and functional outcome 7 years after index admission. J Clin Psychiatry 2010; 71 716-28

15 Chang WC, Tang JT, Hui CL,Lam MM, Chan SK, Wong GH, et al. Prediction of remission and recovery in young people presenting with first-episode psychosis in Hong Kong: a 3-year follow-up study. Aust N Z J Psychiatry 2012 46: $100-8$.

16 Melau M, Jeppesen P, Thorup A, Bertelsen M, Petersen L, Gluud C, et al The effect of five years versus two years of specialized assertive intervention for first episode psychosis: OPUS II: study protocol for a randomized controlled trial. Trials 2011; 12: 72.

17 Malla A. A randomised controlled evaluation of 'extended specialised early intervention service' versus 'regular care' for management of early psychosis over the five year critical period. International Standard Randomised Controlled Trial Number Register ISRCTN11889976.

18 So SHW. Implementing Psychological Intervention Programme in Early Psychosis (PIPE). In Early Psychosis Intervention: A Culturally Adaptive Clinical Guide (eds EYH Chen, H Lee, GHK Wong, GHY Wong): 137-57. Hong Kong University Press, 2013.

19 International Early Psychosis Association Writing Group. International clinical practice guidelines for early psychosis. Br J Psychiatry 2005; 187 (suppl. 48): s120-4.

20 American Psychiatric Association. Diagnostic and Statistical Manual of Mental Disorders (4th edn) (DSM-IV). APA, 1994.

21 So E, Kam I, Leung CM, Chung D, Liu Z, Fong S. The Chinese-bilingual SCID-I/P Project: Stage 1: reliability for mood disorders and schizophrenia. HK J Psychiatry 2003; 13: 7-18.

22 Hafner $\mathrm{H}$, Riecher-Rossler $\mathrm{A}$, Hambrecht M, Maurer $\mathrm{K}$, Meissner $\mathrm{S}$, Schmidtke A, et al. IRAOS: an instrument for the assessment of onset and early course of schizophrenia. Schizophr Res 1992; 6: 209-23.

23 Kay SR, Opler LA, Fiszbein A. Positive and Negative Syndrome Scale (PANSS) for schizophrenia. Schizophr Bull 1987; 13: 261-76.

24 Addington D, Addington J, Maticka-Tyndale E. Assessing depression in schizophrenia: the Calgary Depression Scale. Br J Psychiatry 1993 (suppl. 22): 39-44.

25 Andreasen NC, Carpenter WT, Kane JM, Lasser RA, Marder SR, Weinberger DR. Remission in schizophrenia: proposed criteria and rationale for consensus. Am J Psychiatry 2005; 162: 441-9.

26 Goldman $\mathrm{HH}$, Skodol AE, Lave TR. Revising Axis-V for DSM-IV: a review of measures of social functioning. Am J Psychiatry 1992; 149: 1148-56.
27 Goodman SH, Sewell DR, Cooley EL, Leavitt N. Assessing levels of adaptive functioning: a Role Functioning Scale. Community Ment Health J 1993; 29 . $119-31$.

28 Woods SW. Chlorpromazine equivalent doses for the newer atypical antipsychotics. J Clin Psychiatry 2003; 64: 663-7.

29 Gibbons RD, Hedeker D, DuToit S. Advances in analysis of longitudinal data. Annu Rev ClinPsychol2010; 6: 79-107.

30 Bertolote J, McGorry P. Early intervention and recovery for young people with early psychosis: consensus statement. Br J Psychiatry 2005; 187 (suppl. 48): s116-9.

31 Alvarez-Jimenez M, Gleenson JF, Henry LP, Harrigan SM, Harris MG, Killackey $E$, et al. Road to full recovery: Iongitudinal relationship between symptomatic remission and psychosocial recovery in first-episode psychosis over 7.5 years. Psychol Med 2012; 42: 595-606.

32 Bowie $\mathrm{CR}$, Reichenberg A, Patterson TL, Heaton RK, Harvey PD. Determinants of real-world functional performance in schizophrenia subjects: correlations with cognition, functional capacity, and negative symptoms. Am J Psychiatry 2006; 163: 418-25.

33 Murphy BP, Chung YC, Park TW, McGorry PD. Pharmacological treatment of primary negative symptoms in schizophrenia: a systematic review. Schizophr Res 2006; 88: 5-25.

34 Cotton SM, Lambert M, Schimmelmann BG, Mackinnon A, Gleeson JF, Berk M, et al. Depressive symptoms in first episode schizophrenia spectrum disorder. Schizophr Res 2012; 134: 20-6.

35 Fenton WS. Depression, suicide and suicide prevention in schizophrenia. Suicide Life Threat Behav 2000; 30: 34-49.

36 Nordentoft $\mathrm{M}$, Laursen TM, Agerbo E, Qin P, Hoyer EH, Mortensen PB. Changes in suicide rates for patients with schizophrenia in Denmark 1981-97: nested case-control study. BMJ 2004; 329: 261

37 Dutta R, Murray RM, Hotopf M, Allardyce J, Jones PB, Boydell J. Reassessing the long-term risk of suicide after a first episode of psychosis. Arch Gen Psychiatry 2010; 67: 1230-7.

38 Kuipers E, Holloway F, Rabe-Hesketh S, Tennakoon L. An RCT of early intervention in psychosis: Croydon Outreach and Assertive Support Team (COAST). Soc Psychiatry Psychiatr Epidemiol 2004; 39: 358-63.

39 Garety PA, Craig TK, Dunn G, Fornells-Ambrojo M, Colbert S, Rahaman N, et al. Specialised care for early psychosis: symptoms, social functioning and patient satisfaction: randomised controlled trial. Br J Psychiatry 2006; 188: $37-45$.

40 Grawe RW, Falloon IRH, Widen JH, Skogvoll E. Two years of continued early treatment for recent-onset schizophrenia: a randomized controlled trial. ActaPsychiatrScand 2006; 114: 328-36.

41 Petersen $L$, Jeppesen $P$, Throup A, Abel MB, Ohlenschlaeger J, Christensen TO, et al. A randomized multicentre trial of integrated versus standard treatment for patients with a first episode of psychotic illness. BMJ 2005; 331: 602-8.

42 Craig TKJ, Garety P, Power P, Rahaman N, Colbert S, Fornells-Ambrojo M, et al. The Lambeth Early Onset (LEO): randomized controlled trial of the effectiveness of specialized care for early psychosis. BMJ 2004; 329 1067-71

43 McGorry PD, Edwards J, Mihalopoulos C, Harrigan SM, Jackson HJ. EPICC: an evolving system of early detection and optimal management. Schizophr Bull 1996; 22: 305-26.

44 Goldberg K, Norman R, Hoch J, Schmitz N, Windell D, Brown N, et al. Impact of a specialized early intervention service for psychotic disorders on patient characteristics, service use, and hospital costs in a defined catchment area. Can J Psychiatry 2006; 51: 895-903.

45 Birchwood $M$, Todd $P$, Jackson $C$. Early intervention in psychosis: the critical period hypothesis. Br J Psychiatry 1998; 172 (suppl. 33): 53-9. 